\title{
Distinct spatial expression patterns of AP-2alpha and AP-2gamma in non-neoplastic human breast and breast cancer
}

\author{
Nicolaus Friedrichs ${ }^{1}$, Richard Jäger ${ }^{2}$, Ellen Paggen ${ }^{1}$, Christian Rudlowski ${ }^{3}$, \\ Sabine Merkelbach-Bruse ${ }^{1}$, Hubert Schorle ${ }^{2}$ and Reinhard Buettner ${ }^{1}$ \\ ${ }^{1}$ Institute of Pathology; ${ }^{2}$ Department of Developmental Pathology, Institute of Pathology, University of Bonn \\ Medical School, Bonn, Germany and ${ }^{3}$ Department of Gynecology and Obstetrics, University Hospital of \\ Heidelberg, Heidelberg, Germany
}

\begin{abstract}
Although transcription factors AP-2alpha and AP-2gamma have been implicated in the control of estrogen receptor (ER) and ErbB-2, their impact for breast cancer is still controversial. To better understand the role of AP-2 proteins in mammary neoplasia, the analysis of their spatial expression pattern in normal breast and breast cancer is required. A total of $\mathbf{5 1}$ specimens of female breast cancer patients and a tissue microarray containing 93 additional female breast cancer cases were immunohistochemically stained for AP-2alpha, AP2gamma, ER and ErbB-2. In 70 cases of the tissue microarray, survival data comprising a period of up to 30 years were present. In non-neoplastic breast tissue, AP-2alpha was expressed in the inner glandular cell layer while AP-2gamma was expressed in the outer myoepithelial cell layer. Ductal carcinoma in situ revealed strongly AP-2alpha-positive tumor cells surrounded by a layer of AP-2gamma-positive myoepithelial cells. In invasive carcinoma, expression of AP-2alpha and AP-2gamma was variable. High expression of ER and AP2alpha showed better survival rates than low expression of these markers. AP-2gamma expression had no effect on survival. These results for the first time reveal a distinct spatial expression pattern of AP-2alpha and AP-2gamma in normal breast and in ductal carcinoma in situ with specific AP-2gamma expression in myoepithelium. High ER and AP-2alpha expression in invasive breast cancer showed favorable survival rates. Therefore, AP-2alpha expression seems to be associated with better prognosis of breast cancer. AP-2gamma expression has no influence on survival reflecting that myoepithelial cells are not involved in the neoplastic process.

Modern Pathology (2005) 18, 431-438, advance online publication, 1 October 2004; doi:10.1038/modpathol.3800292
\end{abstract}

Keywords: AP-2; transcription factor; immunohistochemistry; breast cancer; tumorigenesis

The AP-2 family of transcription factors consists of five homologous $50 \mathrm{kDa}$ proteins, AP-2alpha, AP2beta, AP-2gamma, AP-2delta, ${ }^{1}$ and AP-2epsilon, ${ }^{2}$ which are encoded by separate genes (reviewed in Hilger-Eversheim et $a l^{3}$ ). These transcription factors homo- or heterodimerize via helix-span-helix motifs and transactivate their target genes by binding to GC-rich consensus sequences in the respective promoter regions. ${ }^{4,5}$ AP-2 proteins have been implicated in the regulation of cell type-specific processes based on their expression in neural, neural crest, kidney and epithelial cells during

Correspondence: Dr N Friedrichs, MD, Institute of Pathology, University of Bonn Medical School, Sigmund-Freud-Strasse 25, 53127 Bonn, Germany.

E-mail: Nicolaus.Friedrichs@ukb.uni-bonn.de

Received 24 May 2004; revised and accepted 30 June 2004; published online 1 October 2004 development. In the adult mammary gland, expression of AP-2alpha, AP-2beta, and AP-2gamma has been documented. ${ }^{6,7}$ Although highlighting the importance of $A P-2$ genes, the embryonic lethal phenotypes of mice lacking AP-2alpha, AP-2beta, or $A P$-2gamma ${ }^{8-11}$ have so far precluded the analysis of their role in mammary development and function. Recently published gene-overexpression studies in transgenic mice suggest that both AP-2alpha and AP-2gamma may control proliferation, apoptosis and differentiation of mammary epithelial cells. ${ }^{7,12}$ Disturbances of these processes may lead to mammary carcinoma. In fact, AP-2 transcription factors have been implicated in human breast cancer. Several studies have linked AP-2gamma expression with the expression of the receptor tyrosine kinase ErbB-2 (encoded by the HER-2/C-neu proto-oncogene), ${ }^{13,14}$ representing a clinical marker for poor prognosis in breast carcinoma. ${ }^{15}$ In mammary tumor 
cell lines, high expression of AP-2alpha and AP2gamma correlated with the expression of the $E r b B$ 2 gene; moreover, the $E r b B-2$ promoter was shown to contain $A P-2$ binding sites and was transactivated by AP-2 proteins in cell transfection studies. ${ }^{14}$ Furthermore, the AP-2gamma gene maps at the genomic locus 20q13.2, which is frequently amplified in breast cancer cell lines and breast carcinomas. ${ }^{16}$ Immunochemical analyses revealed a correlation between AP-2alpha and AP-2gamma expression and ErbB-2 expression in breast tumor specimens, whereas AP-2alpha alone was associated with positivity for estrogen receptor (ER) expression, a clinical marker for a favorable prognosis. ${ }^{6}$ The estrogen receptor gene had previously been shown to be controlled by AP-2. ${ }^{17}$ These results, however, were questioned by a different study, which found AP-2 expression to be higher in normal breast epithelia than in invasive tumors ${ }^{18}$ confirming a previous study, which had suggested that $A P-2$ might represent a novel tumor-suppressor gene because AP-2alpha/beta inversely correlated with ErbB-2 in invasive breast carcinoma. ${ }^{19}$ To our knowledge, none of the studies addressed the spatial expression patterns of the different AP-2 isoforms on either normal breast tissue or breast tumor specimens. However, this issue may be of crucial importance to resolve the controversial findings concerning the roles of AP-2 proteins in breast cancer. We therefore analyzed the spatial distribution of AP-2alpha and AP-2gamma in breast tumor specimens using specific antibodies. Our results for the first time show distinct spatial patterns of these AP-2 isoforms in non-neoplastic breast epithelia and breast tumors.

\section{Material and methods}

\section{Patients}

Samples from 51 female patients treated for invasive breast cancer in 1999 to 2002 were analyzed in the Department of Pathology, University of Bonn Medical School, Germany. The study collective has been intensively characterized previously with respect to tumor stage, tumor grade and HER2/neu status. ${ }^{20}$

In addition, a tissue microarray containing 93 additional cases collected at the Department of Gynecology and Obstetrics, University of Heidelberg, Germany was analyzed. To account intratumoral heterogeneity two tissue samples per case have been mounted on the tissue microarray. Therefore, a total number of 186 staining intensity values have been analyzed. A total of 70 cases on this tissue microarray included detailed follow-up data comprising a period of up to 30 years.

Combining both patient collectives, 144 patients have been evaluated concerning AP-2alpha-, AP2gamma-, ER- and ErbB-2-(HER2/neu) staining intensities.
Hematoxylin-eosin (H\&E) staining was performed for routine pathological evaluation followed by staining and subsequent evaluation of AP-2alpha, AP-2gamma, ER, ErbB-2, cytokeratin 18 and smooth muscle actin.

\section{Immunohistochemistry}

Staining procedure for AP-2alpha and AP-2gamma Tissue sections were incubated overnight at $60^{\circ} \mathrm{C}$, deparaffinized for $2 \times 10 \mathrm{~min}$ in xylene followed by $5 \mathrm{~min}$ in $100 \%$ ethanol and $20 \mathrm{~min}$ in methanol/ $\mathrm{H}_{2} \mathrm{O}_{2}$. Then slides were put for $5 \mathrm{~min}$ in $96 \%$ and subsequently in $70 \%$ ethanol and for another $5 \mathrm{~min}$ in distilled water. For better antigen retrieval, samples were boiled in a microwave oven in citrate buffer pH 6.0 (AP-2alpha $5 \times 5$ min and AP-2gamma $3 \times 5 \mathrm{~min}$ ). Then samples were washed in PBS for $5 \mathrm{~min}$ and incubated for $15 \mathrm{~min}$ in $10 \%$ normal horse-serum (Vector Laboratories, Burlingame, USA). The samples were incubated for $1 \mathrm{~h}$ at $37^{\circ} \mathrm{C}$ with rabbit anti-human AP-2alpha antibody (Cat. No.: 1600003, Geneka Biotechnology Inc., USA) used at a dilution of 1:200 or with rabbit anti-human AP-2gamma antibody (H-77, Santa Cruz, USA) at a dilution of 1:50, respectively. The samples were washed twice for $5 \mathrm{~min}$ in PBS and then incubated at $20^{\circ} \mathrm{C}$ for $30 \mathrm{~min}$ with the biotinylated secondary antibody in an avidin-biotinylated peroxidase complex-reagent (Vectastain Rabbit ABC elite kit; Vector Laboratories), followed by washing in PBS and subsequent visualization with diaminobenzidine tetrahydrochloride (DAB, Sigma, Munich, Germany). After a final washing step, slides were counterstained with Mayeŕs hematoxylin, dehydrated and mounted.

\section{Staining procedure for cytokeratin 18, smooth} muscle actin, ER and ErbB-2

Immunohistochemical stainings for cytokeratin 18, smooth muscle actin and ER were performed by indirect immunoperoxidase as described in detail previously. ${ }^{21}$ Immunohistochemical staining of ErbB-2 was performed using HercepTest (DAKO, Glostrup, Denmark) as described before. ${ }^{22}$

\section{Evaluation of immunohistochemical staining}

Evaluation of HercepTest was performed observing the staining pattern of cell membranes as set in the criteria specified by Dako for interpretation. According to the intensity of membrane staining a score was established.

Staining intensity of AP-2alpha and AP-2gamma was evaluated by two different observers. Also immunohistochemistry for ER and ErbB-2 was scored independently by two different pathologists. Evaluation of AP-2alpha, AP-2gamma and ER was performed using a score according to Remmele and Stegner $^{23}$ in order to achieve comparable values. Nuclear AP-2alpha staining of the inner glandular cell layer and nuclear AP-2gamma staining of the 
outer myoepithelial cell layer in normal breast tissue within the slide was serving as internal control. Score value was 0 if no staining was present. Score 1 was used if $\leq 10 \%$ of cells were stained, score 2 if $10-50 \%$, score 3 if $51-80 \%$ and score 4 if more than $80 \%$ of cells showed immunohistochemical staining reaction. The result of this score was multiplied with the staining intensity score value. Staining intensity was set to score value 0 if no staining was present. Score 1 was used if weak staining of cells was observed, score 2 moderate and score 3 if strong staining of cells was present. Thus, final scores ranged between a minimum of 0 point and a maximum of 12 points.

\section{In Vitro Translation of Proteins and Western Blot}

In vitro transcription and translation of $A P-2 a l p h a$ or AP-2gamma were carried out using the TNT Quick Coupled Transcription/Translation System (Promega, Madison, USA) following the manufacturer's instructions. Briefly, $1 \mu \mathrm{g}$ of plasmid DNA containing the human AP-2alpha or AP-2gamma cDNA, respectively, was in vitro transcribed using T7 RNA polymerase, and transcripts were translated into protein using rabbit reticulocyte lysate in a one-tube reaction. Plasmids used were pCMX-AP2alpha, ${ }^{24}$ pT7 $\beta$ NcoAP-2gamma (kindly provided by Dr D Taverna, Institute for Cancer Research and Treatment, Candiolo, Italy) and pCMX-pL1 as empty control vector. In all, $13 \mu \mathrm{l}$ of translated protein was mixed with $20 \mu \mathrm{l} 8 \times$ sample buffer $(600 \mathrm{mM}$ Tris $\mathrm{pH}$ 6.8, $8 \%(\mathrm{w} / \mathrm{v}$ ) SDS, $20 \%(\mathrm{v} / \mathrm{v}) \beta$-mercapto-ethanol) and heated to $100^{\circ} \mathrm{C}$ for $10 \mathrm{~min}$. A volume of $11 \mu \mathrm{l}$ of this solution was separated using a 10\% SDSpolyacrylamid gel ${ }^{25}$ and transferred to a PVDF membrane by electroblotting. After blocking in 10\% (w/v) dry milk in PBS, the membrane was incubated with the same anti-AP2 antibodies as described for immunohistochemistry and a peroxidase-conjugated anti-rabbit antibody and detected using the ECL system (Amersham, Little Chalfont, UK).

\section{Statistical Analysis}

Spearman's rank correlation analysis was applied to examine relationships between immunohistochemical staining intensities of AP-2alpha, AP-2gamma, ER and ErbB-2 using SPSS 12.0.1 software (SPSS Inc., Chicago, USA). A $P$-value of $\leq 0.01$ was considered significant.

Prognostic value of immunohistochemical AP2alpha-, AP-2gamma- and ER- staining intensity was analyzed with regard to overall survival using Wilcoxon (Gehan) test.

\section{Results}

We studied a collective of 51 female breast cancer cases that were described in detail previously. ${ }^{20}$ In addition, a tissue microarray containing 93 cases of invasive female breast cancer with detailed followup data of 70 cases comprising 30 years was included in our study. All 144 cases were analyzed immunohistochemically using commercially available antibodies directed against AP-2alpha and AP2gamma. Specificity of these antibodies for the particular AP-2 isoforms was first evaluated by Western blot analyses using in vitro-translated AP-2 proteins. As shown in Figure 1, the AP2alpha-specific antibody did not crossreact with AP-2gamma protein, and, vice versa, the AP-2gamma-specific antibody H-77 did not bind to AP2alpha protein whereas each of the antibodies detected its respective antigen. As a control, a nonselective AP-2 antibody reacted both with AP2alpha and AP-2gamma.

In non-neoplastic breast, immunohistochemistry revealed nuclear staining for AP-2alpha in differentiated ductal and lobular epithelia analogous to the staining pattern of the antibody cytokeratin 18 (Figure 2a and b). We detected exclusively nuclear AP-2 staining, but no cytoplasmatic immunosignals. Only in a few cases weak cytoplasmatic staining was observed, which we considered nonspecific as these signals were not reproducible at higher antibody dilution (data not shown). Remarkably, AP-2gamma was not expressed in the cytokeratin 18-positive epithelia but was specifically detected in the nuclei of myoepithelial cells of the basal ductal and lobular epithelia, which were also positive for the myoepithelial marker smooth muscle actin (Figure 2c and d).

In ductal carcinoma in situ, a similar staining pattern of AP-2alpha and AP-2gamma was noticed. An outer wall of AP-2gamma-positive myoepithelial cells was separating AP-2alpha-positive, polymorphic tumor cells from the stroma (Figures 3ae). Often staining reaction of AP-2alpha was more intensive in ductal carcinoma in situ than in invasive tumor (Figure $3 \mathrm{~b}$ ). There was no difference in AP-2alpha and AP-2gamma staining intensities among tumor cells of pure DCIS cases (see Figure 7 in Supplementary information).
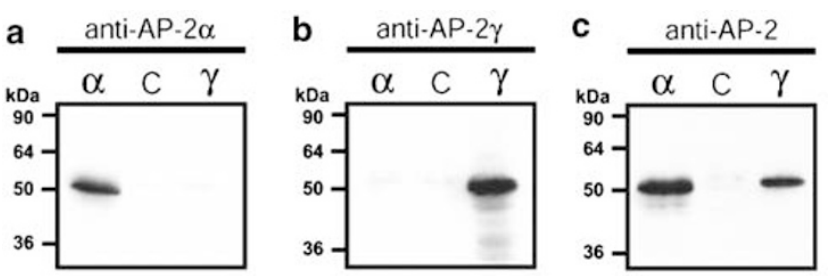

Figure 1 Specificity of AP-2 isoform-specific antibodies. In vitrotranslated AP-2alpha $(\alpha)$, AP-2gamma $(\gamma)$ proteins or control reaction (c) were gelelectrophoretically separated and after Western blotting reacted with antibodies specific for AP-2. (a) Detection using the AP-2alpha-specific antibody. (b) Detection using the AP-2gamma-specific antibody H-77. (c) Detection using the pan-reactive antibody C-18 that recognizes both AP-2alpha and AP-2gamma. 

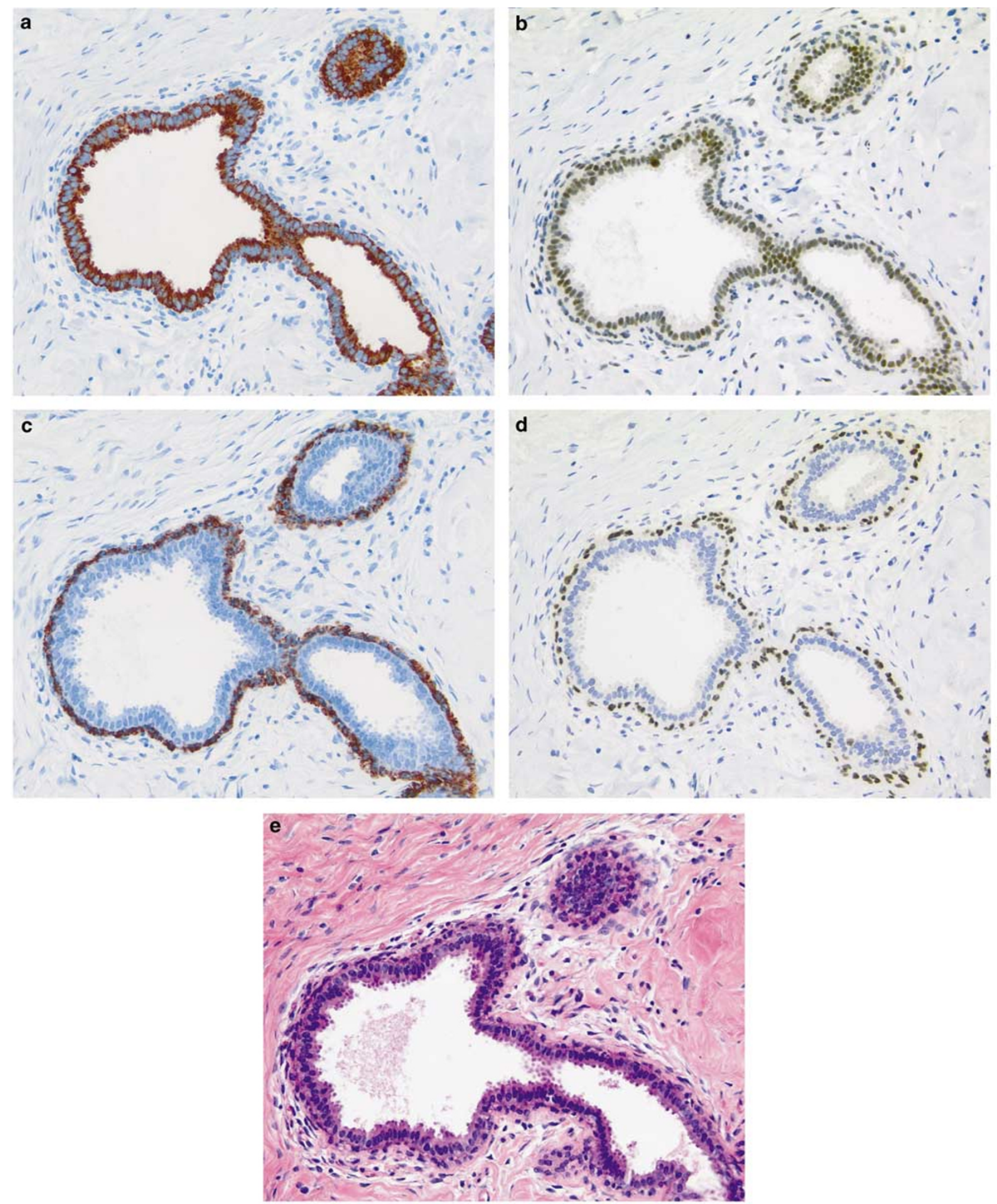

Figure 2 Staining pattern of cytokeratin 18 (a), AP-2alpha (b), smooth muscle actin (c), AP-2gamma (d) and hematoxylin-eosin (e) in non-neoplastic breast tissue $(\times 200)$.

In invasive carcinoma variable AP-2alpha (Figure 4) and AP-2gamma staining of the tumor cells was observed. Undifferentiated carcinomas occasionally expressed AP-2alpha and AP- 2gamma simultaneously. In all cases, nonatypical AP-2gamma-reacting cells with myoepithelial morphology were absent in invasive tumor sections. 

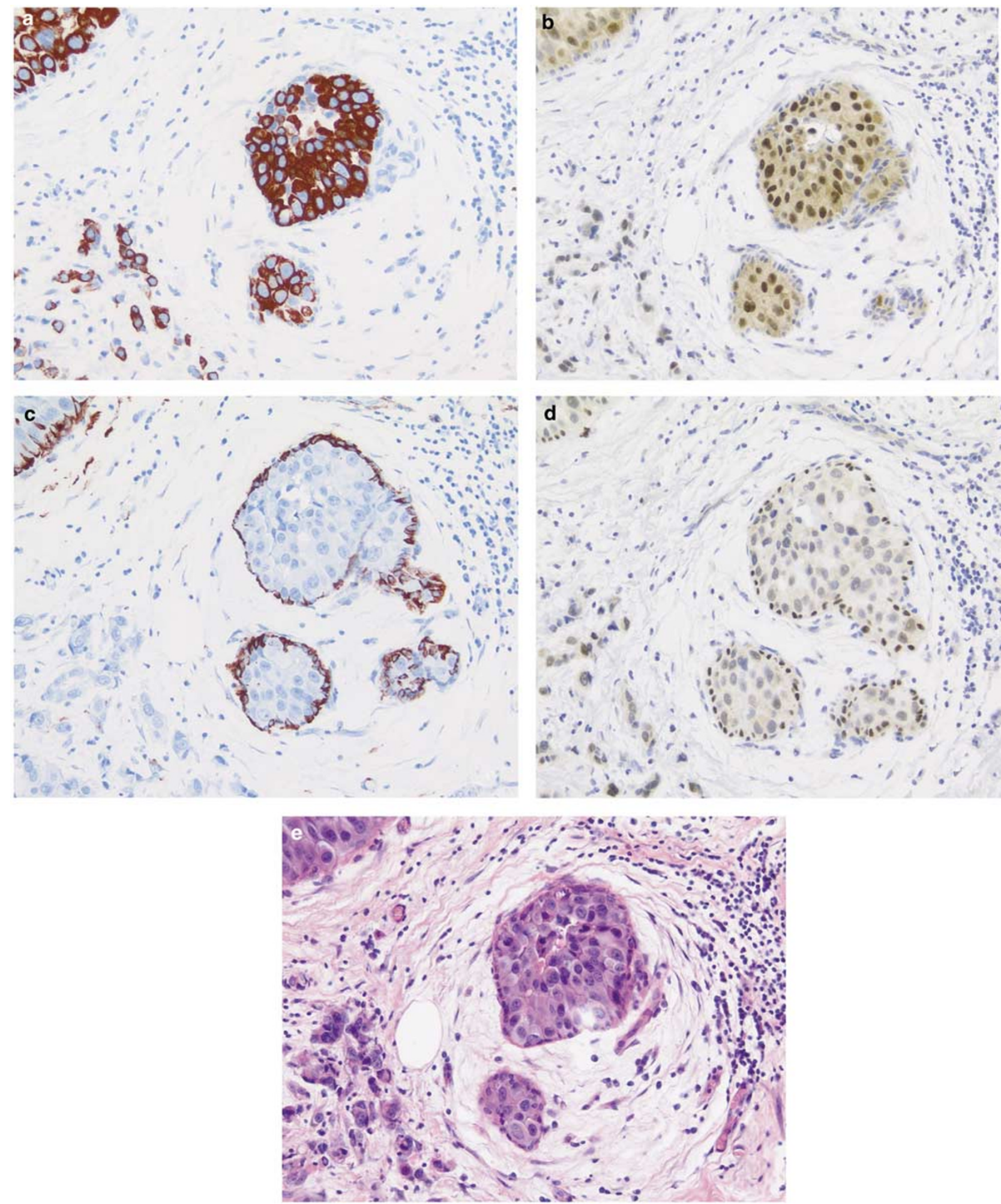

Figure 3 Staining pattern of cytokeratin 18 (a), AP-2alpha (b), smooth muscle actin (c), and AP-2gamma (d) and hematoxylin-eosin (e) in ductal carcinoma in situ $(\times 200)$.

In Spearman's rank correlation analysis, of all 144 cases the intensity of AP-2alpha expression showed a weak but significant correlation to ER $(P<0.001, r=0.237)$ (see Figure 6 in Supplementary information), AP-2gamma $(P<0.001, \quad r=0.448)$ and ErbB-2 $(P<0.001, r=0.332)$. AP-2gamma did not show a correlation to ER $(P=0.963, r=0.003)$ or ErbB-2 $(P=0.043, r=0.138)$. ER staining correlated inversely with tumor malignancy grade $(P=0.016, \quad r=-0.313)$. With regard to $\mathrm{T}-$ and 

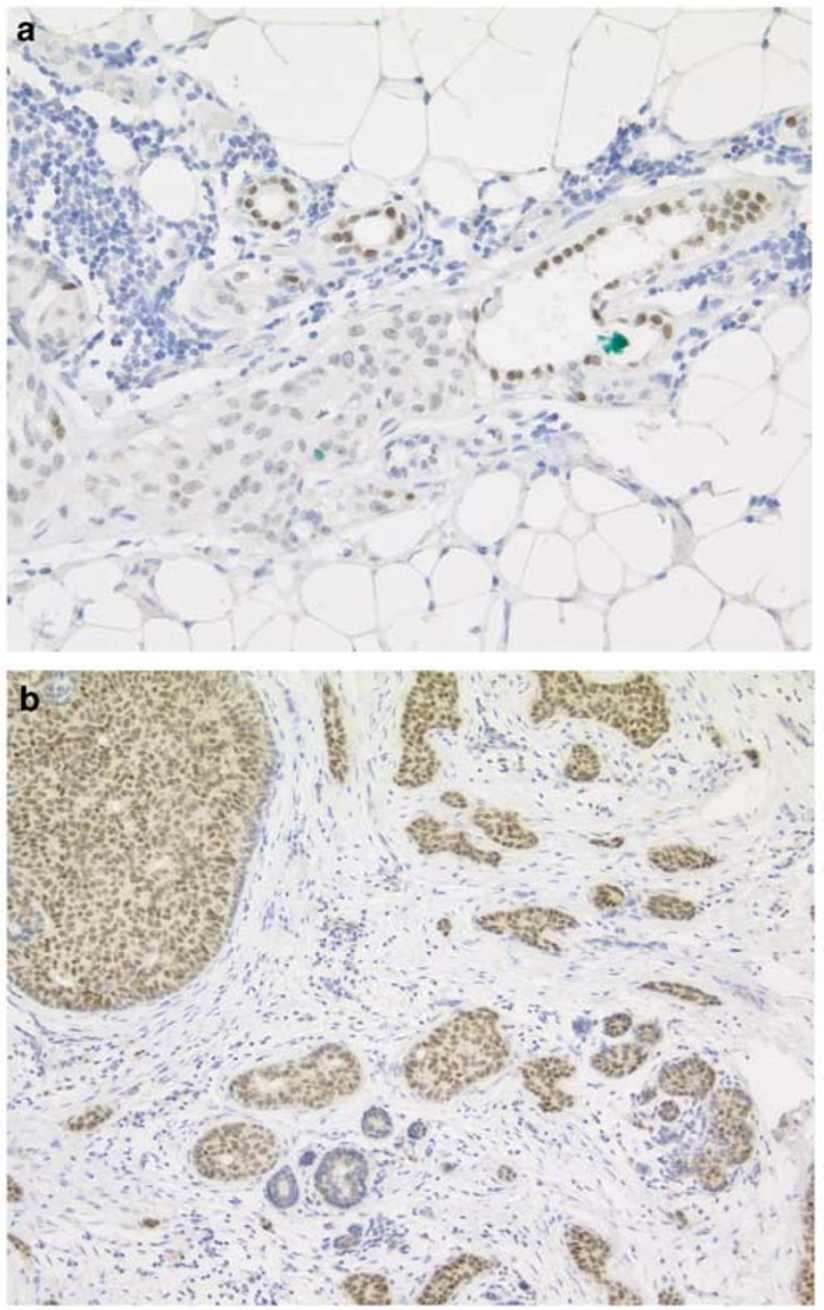

Figure 4 Staining intensity of AP-2alpha in two different cases of invasive ductal carcinoma: a case with weak AP-2alpha staining in invasive tumor (a) and a second case with intensive AP-2alpha staining in invasive carcinoma (b). Note intensive staining of AP2alpha in adjacent non-neoplastic breast epithelia serving as internal staining control $(\times 100)$.

$\mathrm{N}$-stage no correlation could be found with staining results.

In the survival analysis of patients with tumors that were immunostained on the tissue microarray, scoring results of AP-2alpha, AP-2gamma and ER were separated into two groups: low expression representing score values from 0 to 6 and high expression showing values from 7 to 12 . Patients showing high expression of ER had a better outcome than those with low expression (Figure 5a) $(P=0.009)$. High AP-2alpha expression also showed a favorable outcome concerning survival, while low AP-2alpha expression was linked to worse prognosis (Figure 5b) $(P=0.131)$. The AP-2alpha overexpressing cohort showed a mean survival rate of 15.0 years and the ER overexpressing group a value of 15.5 years. In contrast, patients with low AP2alpha expression in breast cancers showed a mean survival rate of 11.0 years while patients with low ER expression reached a value of 11.0 years. Immunohistochemical expression of AP-2gamma had no effect on survival (Figure 5c) $(P=0.562)$. The AP-2gamma high expressing group had a value of 12.0 years and the low expressing group a mean survival rate of 11.5 years.

\section{Discussion}

Using AP-2alpha- and AP-2gamma-specific antibodies, we here demonstrate distinct spatial distribution of both AP-2 isoforms in non-neoplastic human breast epithelia. AP-2alpha-positive cells represent cytokeratin 18-positive glandular epithelial cells and AP-2gamma-positive cells represent SMA-positive myoepithelia. In early and well-differentiated breast cancer, the expression of AP-2 seems to reflect the epithelial compartment contributing to the tumor. Therefore, in Ductal carcinoma in situ both AP-2alpha and AP-2gamma are found expressed in a spatial distribution resembling normal epithelia with AP-2gamma representing the SMA-positive myoepithelial barrier surrounding the AP-2alphapositive tumor cells. Invasive areas lack myoepithelia and hence AP-2gamma-positive cells with myoepithelial morphology disappear while AP2alpha-positve tumor cells remain. Undifferentiated tumors may also show AP-2gamma-positive, atypical tumor cells that either reflect the acquisition of myoepithelial markers as a consequence of losing normal epithelial differentiation, or may also reflect aberrant AP-2 expression patterns.

Previous studies did not report the nonoverlapping spatial expression patterns of AP-2alpha and AP-2gamma in normal breast tissue, most likely due to applying antibodies with partly overlapping specificity for the highly conserved AP-2 isoforms. For instance, the antibody used by Gee et $a 1^{19}$ only detected AP-2alpha and AP-2beta, and thus AP2gamma could not be analyzed. The AP-2 antibody employed in the study of Pellikainen et $a l^{18}$ has a much higher sensitivity for AP-2alpha and AP-2beta than for AP-2gamma and thus the latter isoform most likely was not stained appropriately. In the study of Turner et $a l^{6}$ no benign tissue was shown, and it is not mentioned whether the antibodies were employed to discriminate between the two epithelial compartments.

In ductal carcinoma, in situ staining reaction of AP-2alpha was often more intensive than in invasive tumor. Therefore, a larger collective of pure DCIS should be studied to clarify the question whether AP-2alpha-overexpressing tumor cells reflecting a 'less malignant' tumor cell clone are generally located in DCIS while invasive tumor cells with low AP-2alpha expression reflect higher malignancy.

Expression of ER is a well-established prognostic marker in breast cancer. High ER expression is 

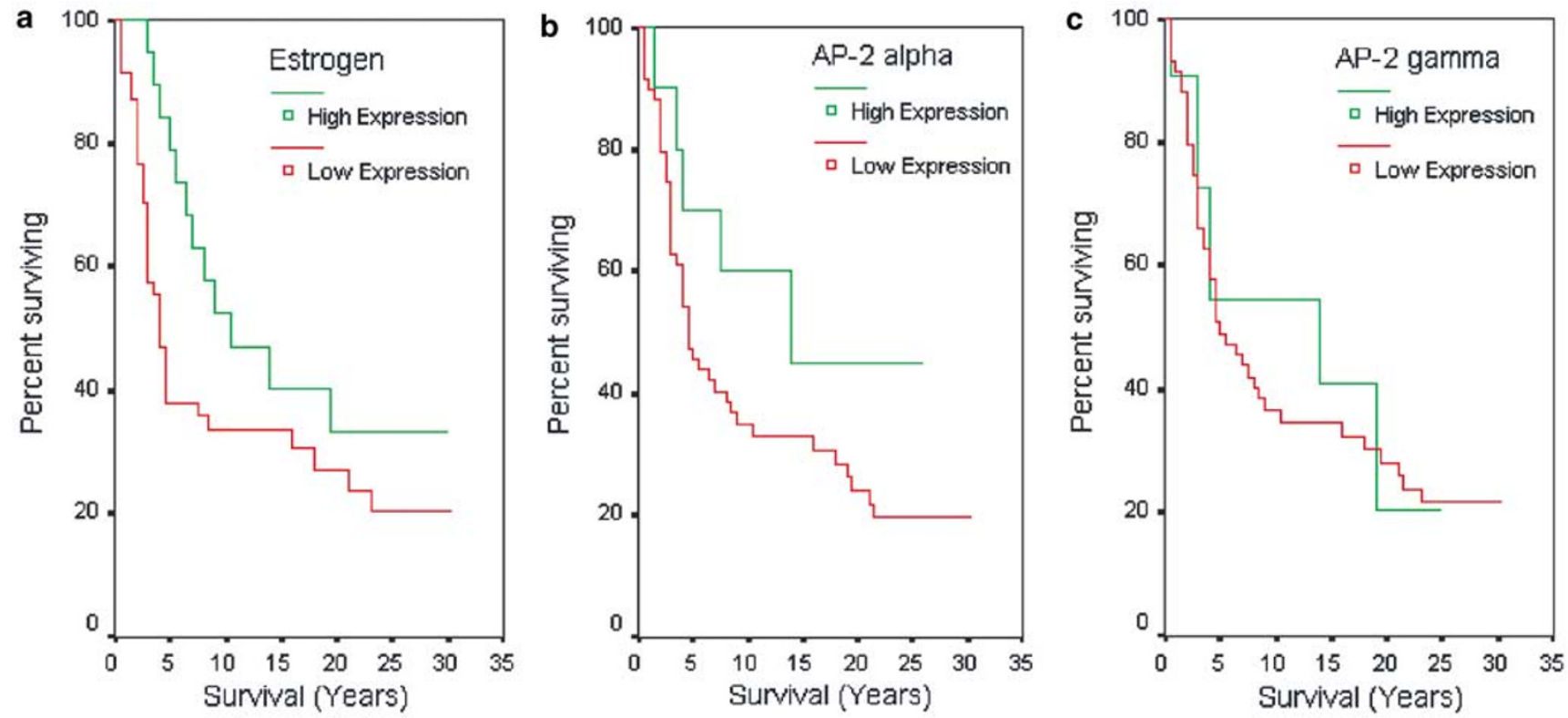

Figure 5 Survival data of 70 female patients with breast cancer in relation to expression intensities of ER (a), AP2alpha (b) and AP-2gamma (c).

linked to a favorable prognosis as shown by Henderson and Patek. ${ }^{26}$ The present study confirmed this finding detecting a better survival rate of ER-overexpressing patients than patients with low or absent ER staining. Furthermore, a weak correlation of ER and AP-2alpha was found; a fact that has also been described by other authors. ${ }^{6,19}$ These findings indicate a comparable diagnostic value of ER- and AP-2alpha-expression in invasive breast cancer.

Analyzing AP-2 expression in invasive breast cancer, Turner et $a l^{6}$ found a significant upregulation of AP-2gamma. In contrast, Pellikainen et $a 1^{18}$ described a significantly lower expression of AP-2 isoforms alpha, beta and gamma in invasive carcinoma compared with normal ductal breast epithelium. According to our results, the expression of the different AP-2 isoforms should be evaluated separately as they represent different histological components contributing to the tumor. In invasive carcinoma, AP-2alpha expressing ductal epithelia seem to be involved in the tumor process in the first line. In contrast, a primary involvement of the myoepithelial-derived protein AP-2gamma in ductal neoplasia seems unlikely. Nevertheless, an extensive AP-2gamma staining of invasive tumor cells was occasionally found in undifferentiated carcinoma. The latter observation could be explained as an adoption of myoepithelial tumor cell characteristics with progression of breast cancer.

Concerning the prognostic value of AP-2 expression in invasive breast cancer, Gee et $a 1^{19}$ found that loss of AP-2alpha and beta expression was associated with disease progression. The authors concluded that AP-2alpha and AP-2beta serve as a tumor suppressor in breast cancer. Nevertheless, these findings were not supported by long-term follow-up data. In the present study, the AP-2alpha overexpressing cohort showed favorable mean survival rates confirming the preceding findings. This fact could indicate a potential role of AP-2alpha as a protective factor in breast tumorigenesis. AP2gamma expression did not have influence on survival rates, reflecting the different histopathological role of myoepithelial cells in breast cancer.

The distinct compartments of mammary epithelium expressing AP-2alpha or AP-2gamma, respectively, point to specific biological functions of the different AP-2 isoforms. The identification of cytokeratin 5-positive mammary stem cells giving rise to both glandular cells and myoepithelial cells ${ }^{27}$ raises the possibility that along these developmental fates, the distinct AP-2 isoforms may behave as genetic switches that control sets of differentiation-specific genes. It will therefore be of interest to identify the particular AP-2 isoform(s) expressed in the mammary stem cell compartment. As breast cancer may arise from these stem cells or CK18/SMA-positive progenitor cells, ${ }^{28}$ this issue is not only of relevance for understanding breast tumorigenesis but may also be important for a refined diagnosis of subtypes of breast cancer.

\section{Acknowledgements}

Grants from the Deutsche Forschungsgemeinschaft (Scho 503, BU672/3-5) to HS and RB supported this work. This work is dedicated to Karl Heinz Friedrichs. 


\section{References}

1 Zhao F, Satoda M, Licht JD, et al. Cloning and characterization of a novel mouse AP-2 transcription factor, AP-2delta, with unique DNA binding and transactivation properties. J Biol Chem 2001;276: 40755-40760.

2 Feng W, Williams T. Cloning and characterization of the mouse AP-2epsilon gene: a novel family member expressed in the developing olfactory bulb. Mol Cell Neurosci 2003;24:460-475.

3 Hilger-Eversheim K, Moser $\mathrm{M}$, Schorle $\mathrm{H}$, et al. Regulatory roles of AP-2 transcription factors in vertebrate development, apoptosis and cell-cycle control. Gene 2000;260:1-12.

4 Williams T, Tjian R. Analysis of the DNA-binding and activation properties of the human transcription factor AP-2. Genes Dev 1991;5:670-682.

5 Williams T, Tjian R. Characterization of a dimerization motif in AP-2 and its function in heterologous DNAbinding proteins. Science 1991;251:1067-1071.

6 Turner BC, Zhang J, Gumbs AA, et al. Expression of AP-2 transcription factors in human breast cancer correlates with the regulation of multiple growth factors signalling pathways. Cancer Res 1998;58: 5466-5472.

7 Zhang J, Brewer S, Huang J, et al. Overexpression of transcription factor Ap-2 alpha suppresses mammary gland growth and morphogenesis. Dev Biol 2003; 256:127-145.

8 Schorle H, Meier P, Buchert M, et al. Transcription factor AP-2 esential for cranial closure and craniofacial development. Nature 1996;381:235-238.

9 Moser M, Pscherer A, Roth C, et al. Enhanced apoptotic cell death of renal epithelial cells in mice lacking transcription factor AP-2beta. Genes Dev 1997; 11:1938-1948.

10 Zhang J, Hagopian-Donaldson S, Serbedzija G, et al. Neural tube, skeletal and body wall defects in mice lacking transcription factor AP-2. Nature 1996;381: 238-241.

11 Werling U, Schorle H. Transcription factor gene AP-2 gamma essential for early murine development. Mol Cell Biol 2002;22:3149-3156.

12 Jäger R, Werling $U$, Rimpf $S$, et al. Transcription factor AP-2gamma stimulates proliferation and apoptosis and impairs differentiation in a transgenic model. Mol Cancer Res 2003;1:921-929.

13 Bosher JM, Williams T, Hurst HC. The developmentally regulated transcription factor AP-2 is involved in C-erbB-2 overexpression in human mammary carcinoma. Proc Natl Acad Sci USA 1995;92: 744-747.

14 Bosher JM, Totty NF, Hsuan JJ, et al. A family of AP-2 proteins regulates c-erbB-2 expression in mammary carcinoma. Oncogene 1996;13:1701-1707.
15 Hynes NE, Stern DF. The biology of erbB-2/neu/HER-2 and its role in cancer. Biochim Biophys Acta 1994; 1198:165-184.

16 Williamson JA, Bosher JM, Skinner A, et al. Chromosomal mapping of the human and mouse homologues of two new members of the AP-2 family of transcription factors. Genomics 1996;35:262-264.

17 McPherson LA, Baichwal VR, Weigel RJ. Identification of ERF-1 as a member of the AP-2 transcription factor family. Proc Natl Acad Sci USA 1997;94:4342-4347.

18 Pellikainen J, Kataja V, Ropponen K, et al. Reduced nuclear expression of transcription factor AP-2 associates with aggressive breast cancer. Clin Cancer Res 2002;8:3487-3495.

19 Gee JM, Robertson JF, Ellis IO, et al. Immunohistochemical analysis reveals a tumour suppressor-like role for the transcription factor AP-2 in invasive breast cancer. J Pathol 1999;189:514-520.

20 Merkelbach-Bruse S, Wardelmann E, Behrens $\mathrm{P}$, et al. Current diagnostic methods of HER-2/neu-detection in breast cancer with special regard to real-time PCR. Am J Surg Pathol 2003;27:1565-1570.

21 Bosserhoff $\mathrm{AK}$, Moser $\mathrm{M}$, Hein $\mathrm{R}$, et al. In situ expression patterns of melanoma-inhibiting activity (MIA) in melanomas and breast cancers. J Pathol 1999; 187:446-454.

22 Birner P, Oberhuber G, Stani J, et al. Evaluation of the United States Food and Drug Administration-approved Scoring and Test system of HER-2 Protein Expression in Breast Cancer. Clin Cancer Res 2001;7:1669-1675.

23 Remmele W, Stegner HE. Recommendation for uniform definition of an immunoreactive score (IRS) for immunohistochemical estrogen receptor detection (ER-ICA) in breast cancer tissue. Pathologe 1987;8: 138-140.

24 Buettner R, Kannan P, Imhof A, et al. An alternatively spliced mRNA from the AP-2 gene encodes a negative regulator of transcriptional activation by AP-2. Mol Cell Biol 1993;13:4174-4185.

25 Laemmli UK. Cleavage of structural proteins during the assembly of the head of bacteriophage T4. Nature 1970;227:680-685.

26 Henderson IC, Patek AJ. The relationship between prognostic and predictive factors in the management of breast cancer. Breast Cancer Res Treat 1998;52: 261-288.

27 Boecker W, Buerger H. Evidence of progenitor cells of glandular and myoepithelial cell lineages in the human adult female breast epithelium: a new progenitor (adult stem) cell concept. Cell Prolif 2003; 36(Suppl 1): 73-84.

28 Boecker W, Moll R, Dervan P, et al. Usual ductal hyperplasia of a breast is a committed stem (progenitor) cell lesion distinct from atypical ductal hyperplasia and ductal carcinoma in situ. J Pathol 2002; 198:458-467.

Supplementary Information accompanies the paper on Modern Pathology website (http://www.nature.com/ mpath). 